\title{
Welcome to the 14th Volume of Future Neurology
}

\author{
Rachel Jenkins*,1 \\ ${ }^{1}$ Future Science Group, Unitec House, 2 Albert Place, London N31QB, UK \\ *Author for correspondence: r.jenkins@futuremedicine.com
}

Published online: 19 February 2019

Keywords: biomarkers $\bullet$ clinical trials $\bullet$ genetics $\bullet$ neurology $\bullet$ neuroscience $\bullet$ personalized therapy $\bullet$ research $\bullet$ social media

To all our readers, we are delighted to welcome you to the fourteenth volume of Future Neurology. We are also excited to welcome you to the first Open Access issue of the journal. Since the launch of this title, we have continued to publish high-quality scientific research and commentary, and the open access model will allow us to share our great content with an even bigger audience.

2018 was another exciting year for the Future Neurology with the continued publication of timely, high quality manuscripts. We are proud to present some of our content highlights within this article.

We would also like to take this opportunity to thank all of our valued Editorial Board members, readers and contributors for their continued support. As we move into 2019, we very much look forward to seeing the journals continuous progression and development.

\section{Content highlights of 2018}

At the time of writing (October 2018), our most read article was an editorial piece entitled 'The burden of oncology promises not kept in glioblastoma' [1]. The paper was authored by Alba Brandes and colleagues from the IRCCS Institute of Neurological Sciences (Bologna, Italy), who discuss the challenges faced in glioblastoma and how immune-oncology still has a bigger role to play in treatment of disease.

Another one of our most popular articles was the research article 'Prehospital notification can effectively reduce in-hospital delay for thrombolysis in acute stroke', aimed to reduce in-hospital intervals for thrombolysis in acute stroke by developing a prehospital notification protocol that directly notifies a neurologist to prepare for possible treatment [2].

Also highly read was another editorial by Michael Motes that discussed whether or not cognitive training was able to improve brain functioning with increasing age [3]. Another highly read article reviewed the role of FABP3 as a potential biomarker in Alzheimer's disease and synucleinopathies [4].

\section{Readership demographics}

It is great to see that in 2018, our journal is being read throughout the world, with the highest number of readers being from the North America (39\%), Europe (30\%) and Asia (23\%) (Figure 1).

\section{Authorship demographics}

It is interesting to see where the journal is receiving its content from; in 2018, authors from Europe submitted the highest volume of content (72\%), followed by North America (14\%) (Figure 2). In terms of country, the highest numbers of submissions were by the USA. We continue to receive high-quality content from across the globe, including an emerging authorship in Asia and Australia.

\section{Social media}

Future Neurology continues to be active across social media including on our Linkedin Future Science Neurology Group [5] and Twitter, @fsgfnl [6]. Our regular posts include journal highlights such as newly published content and the latest neurology news. This year, we have thoroughly enjoyed engaging with oncology professionals across the field and we welcome readers to connect with us on various forms of social media going into 2019. 


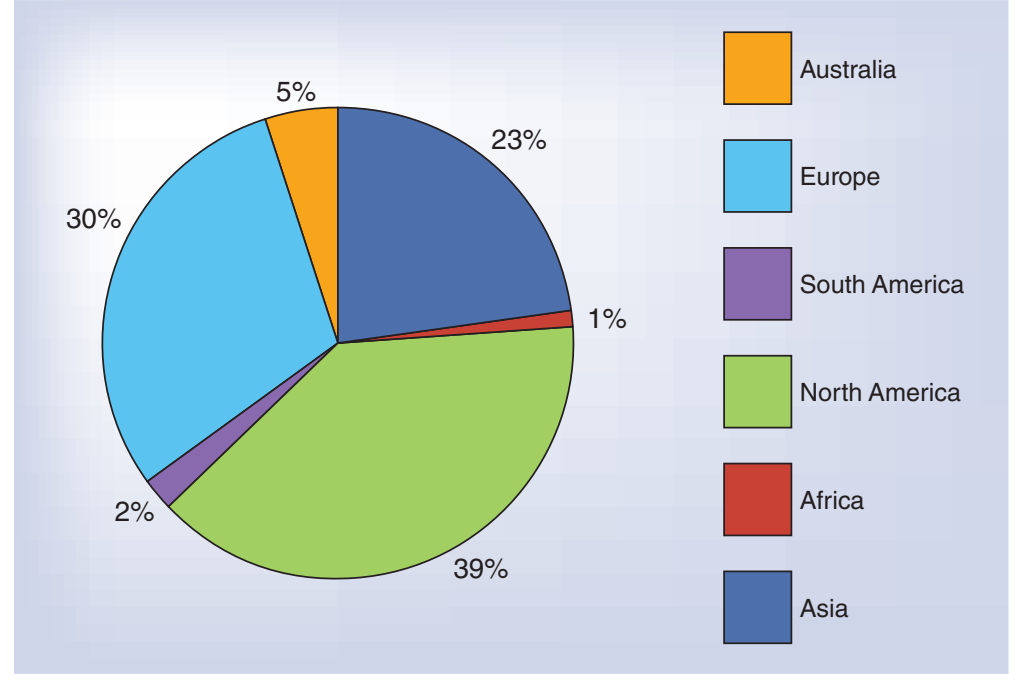

Figure 1. Proportion of readership demographics for Future Neurology in 2018.

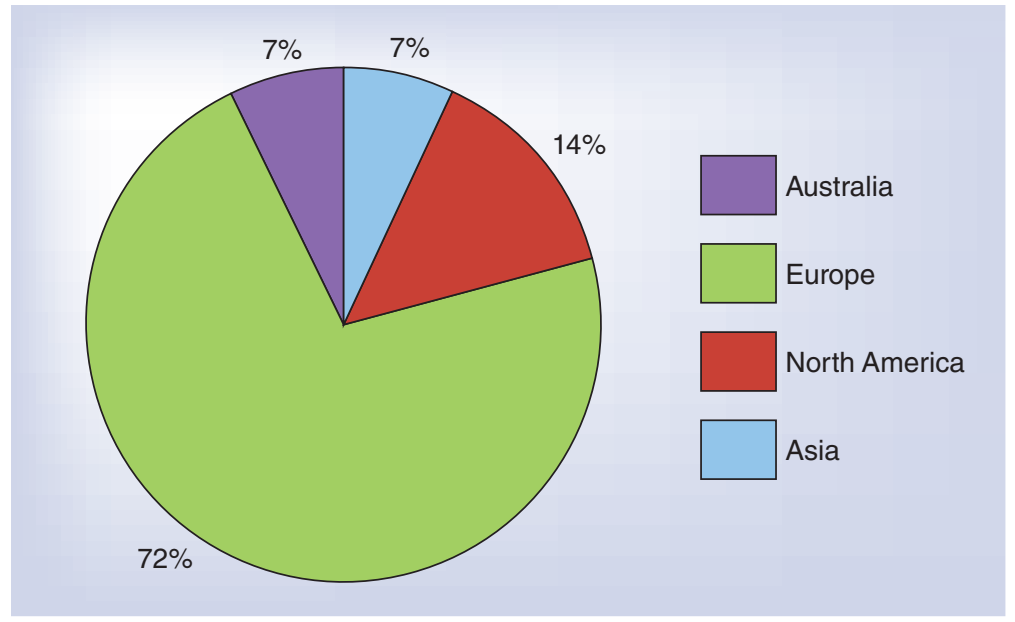

Figure 2. Proportion of authorship demographics for Future Neurology in 2018.

\section{Conclusion}

We appreciate all feedback from the neurology community regarding the direction of our content such as 'hot topics' in the field and trends that you feel should be covered in Future Neurology. We welcome unsolicited article proposals, and would be delighted to hear from you. In particular, we encourage submissions on novel and translational work such as:

- Understanding biological processes within the nervous system.

- Mechanisms and pathologies of disease, injury and disorder including neuropsychiatry.

- Disease modeling systems utilizing computer, in vitro and animal approaches.

- Genetic factors and precision medicine.

- Diagnostic and prognostic advances in screening, biomarker and imaging approaches, in addition to their application in the clinic.

- Disease risk assessment and epidemiological studies.

- Improving current management and treatment approaches.

- Identification of novel therapeutic targets and drug delivery systems.

- Drug development, clinical testing and safety.

- Novel and emerging therapeutics including cell therapy, gene therapy, nanomedicine, immunotherapy and bioelectronics.

- Real-world evidence and outcomes research. 
We greatly look forward to collaborating with you all over the next year and hope Future Neurology continues to fulfill its role in the medical community and grow and develop as a journal.

\section{Financial \& competing interests disclosure}

$R$ Jenkins is an employee of Future Medicine Ltd. The author has no other relevant affiliations or financial involvement with any organization or entity with a financial interest in or financial conflict with the subject matter or materials discussed in the manuscript apart from those disclosed.

No writing assistance was utilized in the production of this manuscript.

\section{Open access}

This work is licensed under the Creative Commons Attribution-NonCommercial-NoDerivatives 4.0 Unported License. To view a copy of this license, visit: http://creativecommons.org/licenses/by-nc-nd/4.0/

\section{References}

1. Lamberti G, Franceschi E, Brandes A. The burden of oncology promises not kept in glioblastoma. Future Neurol.13(1), 1-4 (2018). www.futuremedicine.com/doi/10.2217/fnl-2017-0033

2. Sadeghi-Hokmabadi E, Farhoudi M, Taheraghdam A et al. Prehospital notification can effectively reduce in-hospital delay for thrombolysis in acute stroke. Future Neurol. 13(1), 5-11 (2018). www.futuremedicine.com/doi/10.2217/fnl-2017-0031

3. Motes M. Is cognitive training able to improve brain functioning with age? Future Neurol. 13(2), 41-44 (2018). www.futuremedicine.com/doi/10.2217/fnl-2018-0007

4. Sepe F Chiasserini D Parnetti L. Role of FABP3 as biomarker in Alzheimer's disease and synucleinopathies. Future Neurol. 13(4), 199-207 (2018). www.futuremedicine.com/doi/10.2217/fnl-2018-0003

5. Future Neurology LinkedIn (2018). www.linkedin.com/groups/8204606/

6. Future Neurology (@fsgfnl) on Twitter (2018). Available from https://twitter.com/fsgfnl 
